\title{
Histodemography of Lymphadenopathy
}

\author{
Nadira Majid1, MA Samad Talukder², Syed Mukarram Ali³
}

\begin{abstract}
Background: Lymph node enlargement presents a clinical problem whose significance can range from trivial to critical, depending on the cause of lymphadenopathy. Diseases involving the lymph node fall primarily into three categories, which include lymphadenitis, metastatic malignancies, malignant lymphoma. It is not feasible to excise every enlarge lymph node. So clinical selection of patients must take place and diagnosis of definite causes of lymphadenopathy by histological examination is essential for appropriate treatment. Objective: The aim was to find the relation and association of proportion of different types of lymphadenopathy with age and gender. Materials and method: This cross sectional study was done in Delta Hospital Limited, Dhaka, Bangladesh during the period of May 2010 to December 2010. A total 88 cases were studied irrespective of age, sex along with clinical diagnosis. Results: Among the study subjects 55.7\% was being benign lesions and remaining were with malignant lesions. Among the benign lesions majority (31.8\%) were tuberculosis with female predominance which commonly occurs below the age of 20 years, where as non-Hodgkin's lymphoma (33.3\%) was the commoner form among malignant cases with male predominance occurs in older age group. Mean ( \pm ) age of benign and malignant cases was 22.1 ( \pm 12.73$)$ years and 44.1 ( \pm 17.37$)$ years respectively. Conclusion: The present study revealed that lymphadenopathy occurs more commonly in the middle age group with predominance of benign lesions. Among the benign lesions tuberculosis is the most common one and non-Hodgkin's lymphoma is the commonest malignant lesion.
\end{abstract}

Keywords: Lymphadenopathy, age, sex.

Delta Med Col J. Jan 2013;1(1):8-12

1. Assistant Professor, Dept. of Pathology, Delta Medical College, Dhaka, Bangladesh.

2. Professor (Honorary), Dept. of Microbiology, Delta Medical College, Dhaka, Bangladesh.

3. Professor (Honorary) of Pathology, Bangladesh College of Physicians \& Surgeons.

Correspondence: Dr. Nadira Majid. e-mail: nadiramajid2009@yahoo.com

\section{Introduction}

Lymph nodes are one of the components of the lymphoreticular system, which also includes the thymus, spleen and tonsils as well as organized lymphoid tissue in the bone marrow and mucosa associated lymphoid tissue (MALT). ${ }^{1}$ Lymph nodes are small, bean - shaped organs with highly organized anatomic and functional compartments. The meaning of lymphadenopathy is disease of the lymph node which is synonymously used with swollen lymph node. Patients with enlarged superficial lymph nodes sometimes require surgical biopsy for diagnosis, and there have been many case series describing the pathology found at biopsy. Not all patients with palpable lymph nodes require biopsy, and the finding of benign disease requiring no further treatment is common. ${ }^{2}$
Lymphadenopathy is caused by the invasion or propagation of either inflammatory cells or neoplastic cells into the node. It results from a vast array of disease processes. ${ }^{3}$

Key risk factors for malignancy include older age, firm, fixed nodal character, duration of greater than two weeks, and supra-clavicular location. Knowledge of these risk factors is critical in determining the management of unexplained lymphadenopathy. ${ }^{4}$

In addition, a complete exposure history, review of associated symptoms, and a thorough regional examination help to determine whether lymphadenopathy is of benign or malignant origin. 5, 6 
Unexplained lymphadenopathy without signs or symptoms of serious disease or malignancy can be observed for one month, after which specific testing or biopsy should be performed. While modern haematopathologic technologies have improved the diagnostic yields of fine-needle aspiration. ${ }^{1,2}$

Although benign lymphadenopathy is common, warning signs suggestive of malignancy include lymph nodes $>2 \mathrm{~cm}$ in diameter, generalized lymphadenopathy with or without hepato splenomegaly or with systemic symptoms. A metastatic solid tumour is always in the differential diagnosis of localized lymphadenopathy particularly in older individuals. ${ }^{7}$

Advanced age ( $>40$ years) suggests malignancy. At younger ages, individuals are more likely to have nonspecific lymphadenitis, infectious mononucleosis, rubella, and toxoplasmosis. ${ }^{8}$

Different studies on age and sex distribution relating lymphadenopathy explored that the relative frequencies of various pathologies present as lymph node enlargement in different age groups and the lesions arising in the lymph node can be found in patients ranging from early to advanced age. ${ }^{9-12}$

Our aim was to find relation of different types of lymphadenopathy with age and gender in our population.

\section{Materials and method}

This cross-sectional study was done on 88 specimen of lymph node biopsy from subjects irrespective of age and sex, from May 2010 to December 2010 in the pathology laboratory of Delta Hospital Limited, Dhaka, Bangladesh. The specimens were received in $10 \%$ Formalin as a routine procedure. Samples without a short history or incomplete requisition form and if poorly fixed or unsuitable for other reasons were excluded. Two blocks were embedded from each of the specimen and processed in the automatic tissue processor and cut about the thickness of 4 micron and stained with Haematoxylin \& Eosin stain for histopathological diagnosis. Data were analyzed by SPSS for Windows version 19.0 and the results were expressed as proportion, and test of significance was done by Student's unpaired t-test. p-value $<0.05$ was considered as the level of significance.

\section{Results}

A total of 88 cases of both sex were enrolled in the study. The study was aimed at assessing the relation between histological subtypes of lymphadenopathy with two major demographic variables age and sex.

Among the 88 subjects 49 had benign lesion (55.7\%) and the rest $(44.3 \%)$ were malignant on histopathological examination.

Table I shows the frequency of different types of benign and malignant lymphadenopathy. The study revealed that tuberculosis was the commonest benign lymphadenopathy whereas non Hodgkin's lymphoma was the most common form of malignant lymphadenopathy.

Table I: Frequency of different benign and malignant lymphadenopathy

\begin{tabular}{llr}
$\begin{array}{l}\text { Histopathological } \\
\text { diagnosis }\end{array}$ & Frequency (\%) \\
\hline Benign $(\mathrm{n}=49)$ & Reactive Hyperplasia & $18(20.5 \%)$ \\
& Tuberculosis & $28(31.8 \%)$ \\
& Sarcoidosis & $03(03.4 \%)$ \\
Malignant $(\mathrm{n}=39)$ & & $11(28.2 \%)$ \\
& Hodgkin's Lymphoma & $13(38.5 \%)$ \\
& Non-Hodgkin's Lymphoma & $13(33.3 \%)$ \\
& Metastatic Carcinoma &
\end{tabular}

Mean age of subjects with benign and malignant lymphadenopathy was $22.10 \pm 12.74$ years and $44.10 \pm$ 17.37 years respectively. The difference was statistically very highly significant $(\mathrm{p}<0.001)$ (Table II).

Table II: Distribution and comparison of age in benign and malignant lymphadenopathy

\begin{tabular}{lccc}
\hline Lymphadenopathy & Age $($ Mean \pm SD) & t-value & p-value \\
\hline Benign $(n=49)$ & $22.10 \pm 12.74$ & 6.15 & $<0.001$ \\
Malignant $(n=39)$ & $44.10 \pm 17.37$ & & \\
\hline
\end{tabular}


Table III shows gender distribution between benign and malignant lymphadenopathy where both the groups showed male predominance $(51.02 \%$ in benign and $58.97 \%$ in malignant).

Table III: Gender distribution of lymphadenopathy

\begin{tabular}{lcc}
\hline Lymphadenopathy & \multicolumn{2}{c}{ Gender } \\
& Male & Female \\
\hline Benign $(\mathrm{n}=49)$ & $25(51.02 \%)$ & $24(48.98 \%)$ \\
Malignant $(\mathrm{n}=39)$ & $23(58.97 \%)$ & $16(41.03 \%)$ \\
\hline
\end{tabular}

Among the three types of benign lymphadenopathy, tubercular lymphadenitis was the most frequent one and it was found more in $<20$ years of age group. (Table IV).

Table IV: Distribution of benign lymphadenopathy in different age group $(n=49)$

\begin{tabular}{llll}
\hline Age group & \multicolumn{3}{c}{ Benign Lymphadenopathy } \\
in years & $\begin{array}{l}\text { Reactive } \\
\text { hyperplasia }\end{array}$ & Sarcoidosis & $\begin{array}{l}\text { Tubercular } \\
\text { lymhadenitis }\end{array}$ \\
\hline$<20$ & $09(18.36 \%)$ & $01(2.04 \%)$ & $14(28.57 \%)$ \\
$21-40$ & $07(14.29 \%)$ & $02(4.08 \%)$ & $12(24.49 \%)$ \\
$41-60$ & $02(4.08 \%)$ & 00 & $02(4.08 \%)$ \\
\hline
\end{tabular}

Table V shows distribution of different types of malignant lymphadenopathy in different age group. There was bimodal age incidence of Hodgkin's lymphoma ( $<20$ years and in between $41-60$ years). Non-Hodgkin's lymphoma and metastatic carcinoma were more common in adult age (41-60 years).

Table V: Distribution of malignant lymphadenopathy in different age group $(n=39)$

\begin{tabular}{llll}
\hline $\begin{array}{l}\text { Age } \\
\text { group } \\
\text { in years }\end{array}$ & $\begin{array}{l}\text { Hodgkin's } \\
\text { lymphoma }\end{array}$ & $\begin{array}{l}\text { Non-Hodgkin's } \\
\text { lymphoma }\end{array}$ & $\begin{array}{l}\text { Metastatic } \\
\text { carcinoma }\end{array}$ \\
\hline$<20$ & $04(10.26 \%)$ & $02(5.13 \%)$ & $01(2.56 \%)$ \\
$21-40$ & $03(7.69 \%)$ & $03(7.69 \%)$ & $02(5.13 \%)$ \\
$41-60$ & $04(10.26 \%)$ & $08(20.52 \%)$ & $07(17.95 \%)$ \\
$>60$ & 00 & $02(5.13 \%)$ & $03(7.69 \%)$ \\
\hline
\end{tabular}

Table VI shows gender distribution of different benign lymphadenopathy. Tubercular lymphadenitis was found more common in both sexes followed by reactive hyperplasia with least occurrence of sarcoidosis.

Table VI: Gender distribution of different benign lymphadenopathy $(n=49)$

\begin{tabular}{lcc}
\hline Benign Lymphadenopathy & \multicolumn{2}{c}{ Gender } \\
& Male & Female \\
\hline Reactive hyperplasia & $11(22.45 \%)$ & $7(14.29 \%)$ \\
Sarcoidosis & $1(2.04 \%)$ & $2(4.08 \%)$ \\
Tubercular lymhadenitis & $13(26.53 \%)$ & $15(30.61 \%)$ \\
\hline
\end{tabular}

Table VII shows the gender distribution of different malignant lymphadenopathy. This study showed that non-Hodgkin's lymphoma was more common in male followed by Hodgkin's lymphoma and metastatic carcinoma. Where as metastatic carcinoma was the commonest form in female followed by Hodgkin's and non-Hodgkin's lymphoma.

Table VII: Gender distribution of different malignant lymphadenopathy $(n=39)$

\begin{tabular}{lcc}
\hline Malignant & \multicolumn{2}{c}{ Gender } \\
Lymphadenopathy & Male & Female \\
\hline Hodgkin's lymphoma & $6(15.38 \%)$ & $5(12.82 \%)$ \\
Non-Hodgkin's lymphoma & $12(30.76 \%)$ & $3(7.69 \%)$ \\
Metastatic carcinoma & $5(12.82 \%)$ & $8(20.51 \%)$ \\
\hline
\end{tabular}

\section{Discussion}

An enlargement of the peripheral lymph nodes is a common clinical presentation of a variety of pathological conditions including reactive hyperplasia, infections, primary \& secondary malignancy, autoimmune disorders, vaccination, etc. 13

Tubercular lymphadenitis (31.8\%) was the commonest benign lesions among the study subjects, followed by reactive hyperplasia (20.5\%) and sarcoidosis (03.8\%). On the other hand non-Hodgkin's lymphoma was more common (38.5\%), followed by Hodgkin's lymphoma 
(28.2\%) and metastatic carcinoma (33.3\%) among the malignant lesions. Reactive hyperplasia was the predominant lesion (51\%) in a study done by Moore et al.14 followed by lymphoma (19\%), metastatic carcinoma (15\%) and tubercular lymphadenitis (15\%). This study revealed that benign lymphadenopathy is more common than malignant. Williamson 15 and Chau et al.16 also reported similar results regarding frequency of benign and malignant lymphadenopathy.

The major discrepancy with the studies done abroad in the occurrence of tuberculosis is that tuberculosis is still a major public health problem in Bangladesh causing about 70,000 deaths each year. This mortality rate (45 deaths per 100,000 populations) is 45 percent higher than the Southeast Asian region average (31 deaths per 100,000 populations). In 2008, the World Health Organization (WHO) ranked Bangladesh sixth among the world's 22 high-burden tuberculosis countries. Half of the adult population in Bangladesh carries the bacteria of tuberculosis. ${ }^{17}$

The rate of malignant categories of lymphadenopathy is very low in childhood, but increases with age. 18 This study also shows that benign lymphadenopathy is more common in younger age and malignant lymphadenopathy is common in older age. Lee, Terry and Lukes ${ }^{19}$ showed in one series of 628 patients undergoing nodal biopsy, benign or self limiting causes were found in 79 of patients younger than 30 years of age, versus $59 \%$ in patients 31 to 50 years of age and $39 \%$ in those older than 50 years.

The incidence of non-Hodgkin's lymphoma is more than Hodgkin's lymphoma and according to sex ratio it has slight male excess and it is more common at 65-70 years of age. The median age of Hodgkin lymphoma is 31 years, first peak at 20-35 years and second at 50-70 years of age with slight male excess. ${ }^{13}$ This study also shows that non-Hodgkin's lymphoma is more frequent than Hodgkin's lymphoma and it is more common in male between the age of 41-60 years. This study also shows bimodal age incidence of Hodgkin's lymphoma, having first peak at $<20$ years of age and second peak at 41-60 years.

Abba et al. 20 revealed that in case of lymphadenopathy in adult, 59.5\% were females and tuberculous lymphadenopathy was the most frequent lesion occurring in 98 subjects $(37.9 \%)$ followed by lymphoma in $85(32.9 \%)$. Tuberculosis was more common in females than males (51\% versus $19 \%)$. In our study tuberculosis is also the commonest cause among the benign lesions and it was more frequent in female below the age of 20 years, but the overall sex ratio of lymphadenopathy differs. This is may be due to sample size.

This study was done on a limited number of patients over a short period of time. Based on the findings of the present study it can be concluded that tuberculosis is the most common cause of lymphadenopathy in Bangladesh which frequently occurs in $<20$ years of age and non-Hodgkin's lymphoma is more common than Hodgkin's lymphoma which is more common in male that occur at older age group.

\section{References}

1. DeMay RM. Lymph nodes. The art \& science of cytopathology exfoliative cytology. Chicago: ASCP Press;1996.p.780-846.

2. Pangalis GA, Vassilakopoulos TP, BoussiotisVA, Fessas P. Clinical approach to lymphadenopathy. Semin Oncol.1993;20:570-82.

3. Williamson HA Jr. Lymphadenopathy in a family practice: a descriptive study of 249 cases. J Fam Pract.1985;20:449-52.

4. Fijten GH, Blijham GH. Unexplained lymphadenopathy in family practice. An evaluation of the probability of malignant causes and the effectiveness of physicians' workup. J Fam Pract.1988;27:373-76.

5. Knight PJ, Mulne AF, Vassy LE. When is lymph node biopsy indicated in children with enlarged peripheral nodes? Pediatrics.1982;69:391-96.

6. Sinclair S, Beckman E, Ellman L. Biopsy of enlarged, superficial lymph nodes. JAMA.1974;228:602-03.

7. Habermann TM, Steensma DP. Lymphadenopathy. Mayo Clin Proc.2000;75:723-32. 
8. Lymphadenopathy - diagnosis and empiric therapy. Printout: Lymphadenopathy-Therapy- Antimicrobe.org. [Internet] [cited 2013 April 18]. Available from: www.antimicrobe.org/new/printout/.../e27revDiagTher apy.htm.

9. Cheng AT, Dorman B. Fine needle aspiration cytology: the Auckland experience. Aust N Z J Surg.1992; $62: 368-72$

10. Schelkun PM, Grundy WG. Fine-needle aspiration biopsy of head and neck lesions. J Oral Maxillofac Surg.1991;49:262-67.

11. Schwarz R, Chan NH, MacFarlane JK. Fine needle aspiration cytology in the evaluation of head and neck masses. Am J Surg.1990;159:482-85.

12. Stevenson DS, Allison RS, Robertson MS, Hamer JW. Aspiration cytology in the diagnosis of head and neck masses: the early Christchurch experience. N Z Med J.1989;102:639-41.

13. Craig JIO, McClelland DBL, Ludlam CA. Blood disorders. In: Boon NA, Colledge NR, Walker BR, Hunter JAA, editors. Davidson's principle \& practice of medicine. 20th edition. Philadelphia PA: Churchil Livingstone Elsevier;2006.p.999-1064.
14. Moore WJ, Murray P, Gouldesbrough D, Bem C. Diagnostic biopsy of lymph node of neck, axilla \& groin: rhyme, reason or chance. Ann R Coll Surg Engl.2008;90(3):221-25.

15. Williamson HA Jr. Lymphadenopathy in a family practice: a descriptive study of 249 cases. J Fam Pract. 1985;20:449-58.

16. Chau I, Kelleher MT, Cunninghum D, Norman AR, Wotherspoon A, Trott P, Rhys-Evans P, Rovere GOD, Brown G, Allen M, Waters JS, Haque S, Murray T, Bishop L. Rapid access multidisciplinary lymph node diagnostic clinic: analysis of 550 patients. Br. J Cancer.2003;88(3):354-61.

17. World Health Organization-Bangladesh. TB prevalence patterns in rural Bangladesh. [Internet] 2010. [cited 2010 Oct 27]. Available from: http://www.whoban.org/ Full_report_TB-10.html.

18. Kelly CS, Kelly RE Jr. Lymphadenopathy in children. Paediatr Clin North Am.1998;45:875-88.

19. Lee Y, Terry R, Lukes RJ. Lymph node biopsy for diagnosis: a statistical study. J Surg Oncol.1980; $14: 53-60$

20. Abba AA, Bamgboye AE, Afzal M, Rahmatullah RA. Lymphadenopathy in adults. A clinicopathological analysis. Saudi Med Journal.2002;23(3):282-86. 